\title{
Coronary revascularization should be a subspecialty focus in cardiac surgery
}

\author{
Michael Mack, $\mathrm{MD},{ }^{\mathrm{a}}$ and David Taggart, $\mathrm{MD}^{\mathrm{b}}$
}

\author{
$\overline{\text { From }}{ }^{\mathrm{a}}$ Baylor Scott \& White Health, Dallas, Tex; and ${ }^{\mathrm{b}}$ Department of Cardiovascular Surgery, Oxford University, \\ Oxford, United Kingdom. \\ Received for publication May 16, 2018; revisions received Aug 7, 2018; accepted for publication Aug 20, 2018; \\ available ahead of print Oct 23, 2018. \\ Address for reprints: Michael Mack, MD, 1100 Allied Dr, Plano, TX 75093 (E-mail: Michael.mack@bswhealth. \\ org) \\ J Thorac Cardiovasc Surg 2019;157:945-7 \\ $0022-5223 / \$ 36.00$ \\ Copyright (C) 2018 by The American Association for Thoracic Surgery \\ https://doi.org/10.1016/j.jtcvs.2018.08.078
}

\section{A really definitive and good accomplishment is today always a specialized accomplishment. \\ -Max Weber, German sociologist and philosopher (1864-1920)}

Subspecialization, perhaps more appropriately termed "super specialization," is increasingly becoming standard practice in many procedure-based medical specialties. There are many examples, such as orthopedic surgery, which has many areas of specialty car, including spine disease, knee specialists, hip specialists, shoulder surgeons, and surgeons who focus specifically on foot and ankle disease. Although there are many practicing general orthopedists, the field has become increasingly subspecialty focused. Likewise, the field of general surgery has increasingly evolved to having specialists in colorectal disease, bariatric surgery, hepatobiliary, and esophageal surgery in addition to general surgeons. Interventional cardiology is now beginning to focus on the 3 specific specialty areas of coronary revascularization, peripheral vascular disease, and structural heart disease, offering an additional year of training in each specific area. Our own specialty of thoracic surgery has increasingly evolved into cardiac, noncardiac thoracic disease, and congenital heart specialists. Within the realm of adult cardiac surgery, we have specialists who focus mainly but not exclusively on heart failure surgery, with specific expertise in transplant and mechanical circulatory support. There is a clear, strong mandate for mitral valve surgical specialists, because there is a clear recognition that mitral valve repair rates for degenerative mitral disease increase with greater experience and annual procedural volumes (Figure 1). ${ }^{1,2}$ Aortic valve disease and thoracic aortic disease are 2 other specialized areas of cardiac surgery with specific catheter-based skill sets now required to be able to offer patients all treatment options, and they thus are being increasingly treated by more narrowly focused specialists.

This emphasis on specific specialty areas within a discipline is an acknowledgment that the level of sophistication revascularization.

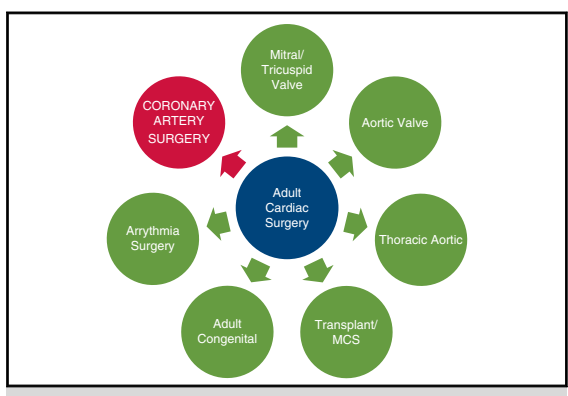

Cardiac surgery is increasingly subspecialized, except for coronary revascularization.

Central Message

Cardiac surgery is becoming more subspecialized; however, coronary artery surgery remains a "generalist" procedure. We propose developing coronary revascularization surgeon specialists and teams.

See Commentary on page 948.

and fund of knowledge required within each area is so great that no one orthopedic surgeon, general surgeon, thoracic surgeon, or cardiac surgeon can "do it all" and do it well. The one specialty area that has not evolved to the focus of a subspecialty within cardiac surgery, however, is coronary

Coronary artery bypass grafting $(\mathrm{CABG})$ is the most common operation performed in cardiac surgery. In the latest report from the Society of Thoracic Surgeons Adult Cardiac Surgery Database, 54\% of all cardiac operations performed $(156,931)$ were isolated $\mathrm{CABG}^{3}$ The volume of operations has remained relatively constant during the past 2 decades, but the operative techniques and outcomes have not significantly changed. ${ }^{4}$ The percentage of operations in which bilateral internal thoracic artery conduits are used has remained at approximately $5 \%$, whereas the number of procedures performed off pump has decreased significantly in recent years. The numbers of minimally invasive coronary bypass operations and of hybrid approaches with percutaneous coronary intervention (PCI) have remained minuscule. Juxtapose this with PCI, for which during the same period there have been significant advances in newer generation drug-eluting stents, techniques to assess lesion severity including functional flow reserve and instantaneous radio free flow reserve, and 


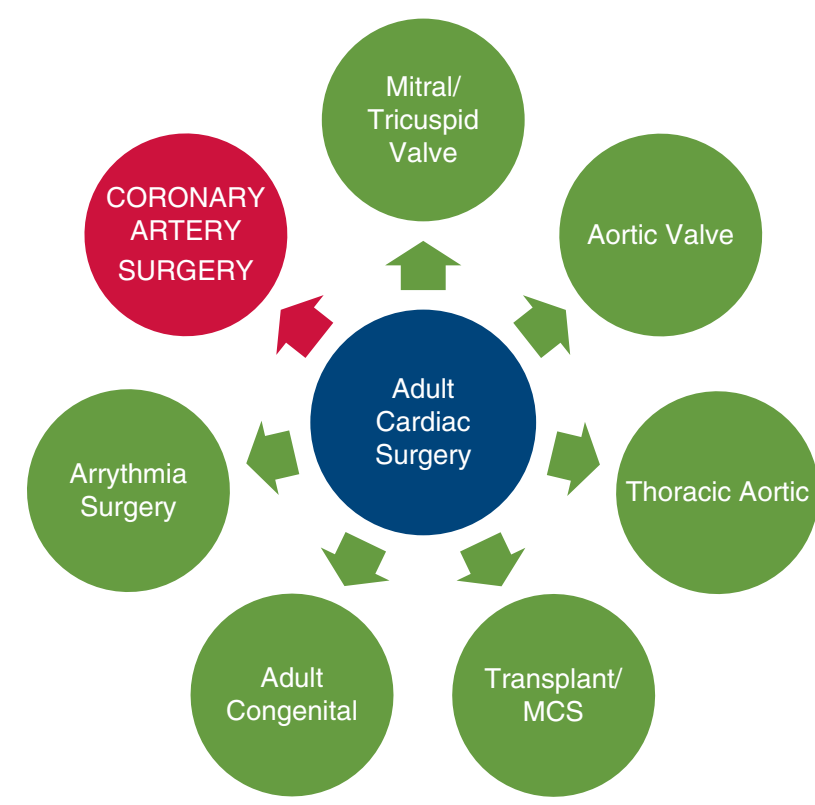

FIGURE 1. Cardiac surgery is becoming increasingly subspecialized, except for coronary revascularization. MCS, Mechanical circulatory support.

closure devices, all of which have served to facilitate the procedure and improve outcomes.

CABG is the operation that catalyzed the field of cardiac surgery, and it remains the core operation performed in our specialty, but it continues to be viewed as a "generalist" procedure. In other words, most or all cardiac surgeons perform it while also performing many other operations in the course of routine practice. This approach, however, is counter to the trends in performance of other procedures in our specialty, as mentioned previously. Our specialty has surgeons who specialize with pride in mitral valve surgery, aortic valve surgery, thoracic aortic procedures, atrial fibrillation surgery, and heart transplantation and mechanical circulatory support.

Very few individuals, however, call themselves "coronary revascularization specialists" and focus specifically on CABG. The procedure that is the most frequently performed and arguably the most technically demanding operation in our specialty, with a few notable exceptions, is treated as a generalist procedure. We would argue that, as a consequence of this, procedure performance and outcomes have not changed substantially during the past 2 decades. ${ }^{4,5}$ The operative mortalities, both observed and risk adjusted, have not improved. The use of a second arterial graft and off-pump surgery, particularly with a no-touch aortic technique that minimizes the risk of cerebral injury, ${ }^{6}$ similarly have not increased. It is important to emphasize that increasing usage rates of these procedures and techniques per se is not the goal; however, we do propose that broader use of all of the tools at our disposal in the hands of the most experienced individuals will lead to better periprocedural and long-term outcomes.

Implicit in this argument for more focused subspecialization is that there is a volume-outcome relationship and that the more one does a procedure, the better one becomes at performing it, thus resulting in better outcomes. The more complex the procedure, the greater this volume-outcome relationship becomes. This has clearly been demonstrated for mitral valve surgery, aortic valve replacement, and CABG. ${ }^{1,2,7,8}$

So, how do we best approach this change? We propose the development of a specialty focus within cardiac surgery of coronary revascularization. Specific individuals within institutions with a passion for the treatment of coronary artery disease should be identified and enabled. Just as mitral valve procedures are steered toward surgeons who have a particular interest and expertise in that disease, surgeons with a focus on coronary revascularization should be recognized and promoted. With the leadership of such individuals, heart teams should be developed in conjunction with coronary interventionalists and general cardiologists with expertise in the medical treatment of coronary artery disease to focus on management of difficult, complex, and high-risk cases of coronary artery disease. Shared decision making with a patient-centric approach would thus be fostered.

Furthermore, there should be a commitment to guideline adherence, public reporting of outcomes, and participation in coronary research trials. Specialty training and education would be a consequence of building this service line approach to treating coronary artery disease. Development of educational forums specifically focused on state-of-theart coronary surgery, such as the International Coronary Congress should be promoted and expanded.

We envision the development of a national or international network of advanced coronary revascularization centers. Numerous predicates for this concept already exist. Those include cancer centers certified by the National Cancer Institute, trauma centers certified by the American College of Surgeons, stroke centers certified by the Brain Attack Coalition, and bariatric surgery centers certified by the American Society of Bariatric Surgery and American College of Surgeons. Recently, a multisociety expert group has proposed a national system of care for valve disease. We envision that a network of coronary revascularization centers would be an inclusive rather than exclusive network of surgeons, teams, and centers that would commit to best practices in the treatment of coronary artery disease. Some initial aspirational goals, practices, and metrics are listed in Table 1. Implicit in this commitment would be the use of most or all tools of surgical coronary revascularization, including multiple arterial revascularization, intraoperative graft flow assessment, off-pump CABG and robotic totally endoscopic coronary artery bypass surgery. 
TABLE 1. Key concepts of optimization of coronary revascularization

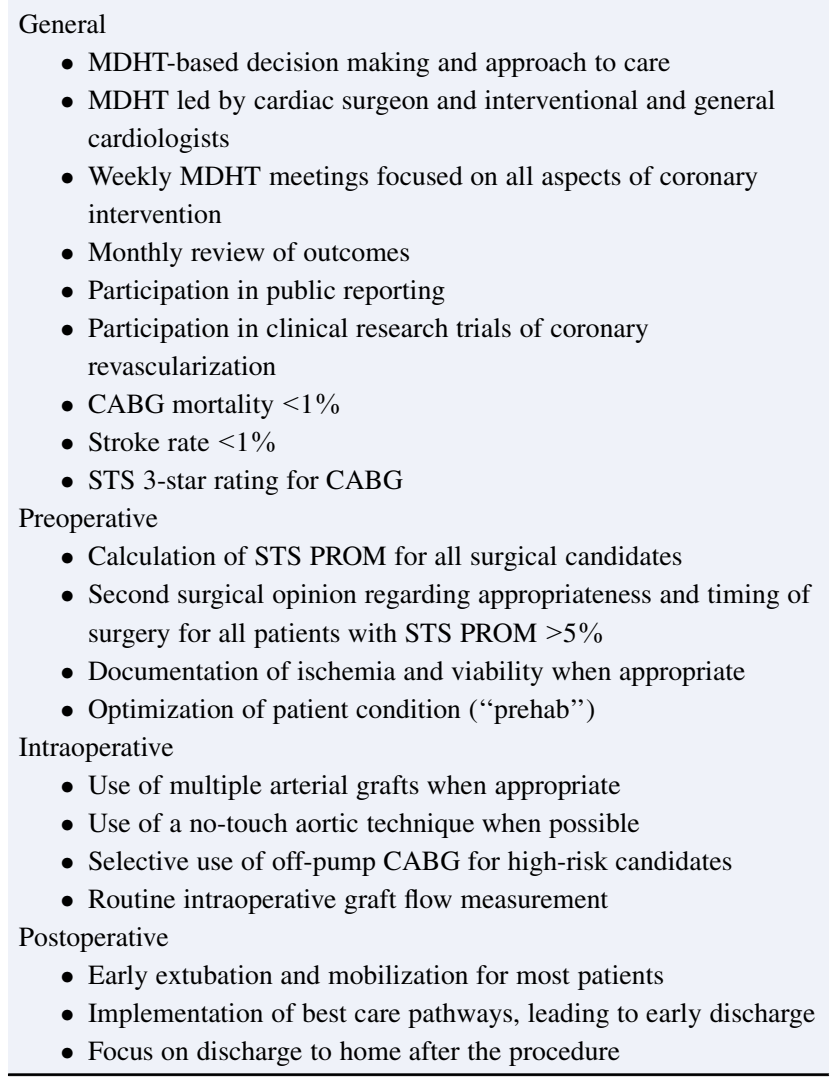

$M D H T$, Multidisciplinary heart team; $C A B G$, coronary artery bypass grafting; $S T S$, Society of Thoracic Surgeons; PROM, predicted risk of mortality.

A key component of an advanced coronary revascularization center would be a similar commitment to best practices in complex PCI, including routine use of functional flow reserve, multivessel stenting, high-risk left main stenting, supported PCI, and expertise in intervention for chronic total occlusions. A network center would also commit to transparency of outcomes and engagement in research trials. Two current randomized clinical trials sponsored by the National Institutes of Health studying hybrid coronary revascularization ${ }^{9}$ and external support of saphenous vein grafts (VEST Trial) ${ }^{10}$ would benefit from an engaged network of centers.

Coronary artery surgery remains the core, bedrock procedure in our specialty. It is time, or arguably past time, to focus on improving the operation by developing an invested group of individuals and centers whose primary focus is on the optimal management of coronary artery disease. There are myriad complexities associated with this proposal that would need to be identified and directly addressed. We think that this would be best accomplished by convening a focus group of experts in coronary revascularization that would conceptualize how to construct and implement a network of best practices, similar to what has been done to address other diseases. To be clear, this is not a proposal to limit access to care or restrict the ability of any surgeon to perform CABG, but rather is intended to create a culture in which "a rising tide lifts all boats" and to improve all aspects of care for patients undergoing coronary revascularization.

\section{Conflict of Interest Statement}

Authors have nothing to disclose with regard to commercial support.

\section{References}

1. Chikwe J, Toyoda N, Anyanwu AC, Itagaki S, Egorova NN, Boateng P, et al. Relation of mitral valve surgery volume to repair rate, durability, and survival. J Am Coll Cardiol. 2017;69:2397-406.

2. Bolling SF, Li S, O’Brien SM, Brennan JM, Prager RL, Gammie JS. Predictors of mitral valve repair: clinical and surgeon factors. Ann Thorac Surg. 2010;90: 1904-11; discussion 1912.

3. D'Agostino RS, Jacobs JP, Badhwar V, Fernandez FG, Paone G, Wormuth DW, et al. The Society of Thoracic Surgeons adult cardiac surgery database: 2018 update on outcomes and quality. Ann Thorac Surg. 2018;105:15-23.

4. Society of Thoracic Surgeons. Executive summary, participant 99999 , STS period ending 09/30/2017. Available at: https://www.sts.org/sites/default/ files/documents/ACSD_ExecutiveSummary2017Harvest4_RevisedReport.pdf.

5. Arsalan M, Mack MJ. Coronary artery bypass grafting is currently underutilized. Circulation. 2016;133:1036-45.

6. Puskas JD, Yanagawa B, Taggart DP. Off-pump, multiple arterial grafting with minimal aortic manipulation: is it for everyone? J Thorac Cardiovasc Surg. 2015; 151:4-6.

7. Birkmeyer JD, Stukel TA, Siewers AE, Goodney PP, Wennberg DE, Lucas FL. Surgeon volume and operative mortality in the United States. $N$ Engl J Med. 2003;349:2117-27.

8. Dewey TM, Herbert MA, Ryan WH, Brinkman WT, Smith R, Prince SL, et al. Influence of surgeon volume on outcomes with aortic valve replacement. Ann Thorac Surg. 2012;93:1107-12; discussion 1112-3.

9. Hybrid Coronary Revascularization Trial. Available at: https://clinicaltrials.gov/ ct2/show/NCT03089398?term =HYBRID\&cond=Coronary + Artery + Disease \& draw $=2 \&$ rank $=11$.

10. VEST Venous Graft External Support Pivotal Study (VEST Pivotal). Available at: https://clinicaltrials.gov/ct2/show/NCT03209609?term $=$ VEST + Trial\& rank $=10$. 